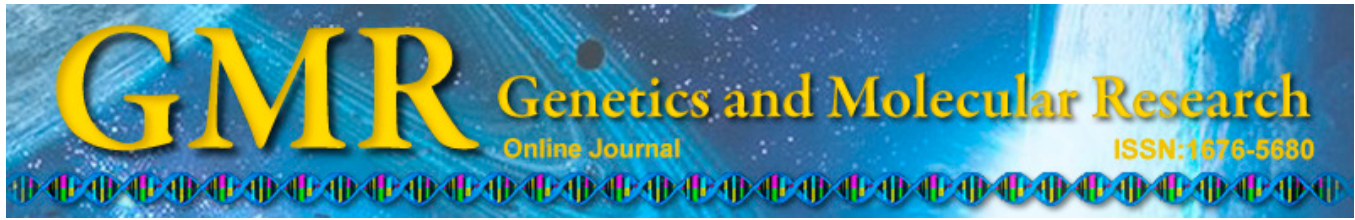

\title{
Genetic variations in microRNA genes and susceptibility to hepatocellular carcinoma
}

\author{
D. Li, J.J. Peng, Y. Tan, T. Chen, D. Wei, M. Du and T. Zhang \\ Department of Oncology, Chengdu Military General Hospital, Chengdu, \\ Sichuan Province, China
}

Corresponding author: T. Zhang

E-mail: heqiang_cmuc@163.com

Genet. Mol. Res. 14 (1): 1926-1931 (2015)

Received January 6, 2014

Accepted March 12, 2014

Published March 20, 2015

DOI http://dx.doi.org/10.4238/2015.March.20.2

\begin{abstract}
We conducted a hospital-based case-control study to investigate the effect of the miR-146aG $>C$ and miR-499A $>$ G polymorphisms on the risk of hepatocellular carcinoma (HCC) in a Chinese population. This study was 1:1 matched case-control study consisting of $184 \mathrm{HCC}$ patients and 184 control subjects. miR-146aG $>\mathrm{C}$ and miR-499A $>\mathrm{G}$ polymorphisms were genotyped by polymerase chain reaction-restriction fragment length polymorphism. Multivariate regression analyses showed that subjects carrying the miR-146a $\mathrm{G}$ allele and miR-499 G allele were associated with a non-significant increased risk of HCC compared with subjects with the homozygous allele, with adjusted odds ratios (95\% confidence interval) of $1.38(0.97-1.84)$ and 1.40 (0.99-2.08), respectively. Moreover, subjects carrying the miR-499 A allele showed a greatly increased risk of HCC in subjects infected with HBV compared with subjects carrying the miR-499 A allele, with an adjusted odds ratio (95\% confidence interval) of 1.53 (1.34-2.41). In conclusion, the miR-146aG $>\mathrm{C}$ and miR-499A $>\mathrm{G}$ polymorphisms do not have a role in the genetic susceptibility to HCC.
\end{abstract}

Key words: HBV; Hepatocellular carcinoma; MicroRNA; Polymorphisms 


\section{INTRODUCTION}

Hepatocellular carcinoma (HCC) is the fifth most common cancer and the third leading cause of cancer death worldwide (Farazi and DePinho, 2006). Hepatitis B virus (HBV) infection is a key risk factor for HCC. Long-term exposure to HBV can induce various diseases such as chronic hepatitis, liver cirrhosis, and hepatocellular carcinoma (Kao and Chen, 2002). However, only $10 \%$ of HBV-infected subjects developed HCC during their lifetime (Yu and Yuan, 2004; Davila et al., 2004). Therefore, both genetic and environmental factors are involved in HCC development (Yu et al., 2004).

MicroRNAs (miRNAs) are a group of small non-coding RNA molecules that have been identified in many organisms and can regulate the expression of genes in a variety of eukaryotic systems (He and Hannon, 2004; Bartel, 2004). MicroRNAs are involved in various processes, such as development, apoptosis, proliferation, and differentiation in eukaryotic cells (Lim et al., 2005; Wilfred et al., 2007). Single-nucleotide polymorphisms (SNPs) are the most common type of genetic variation in the human genome. SNPs in protein-coding genes reportedly influence protein functions and individual susceptibility to cancers (Loktionov, 2004). miR-146aG $>C$ and miR-499 $A>G$ polymorphisms were reported to be associated with various cancers (Hu et al., 2009; He et al., 2012). Several recent studies reported that miRNA polymorphisms are associated with HCC risk, but the results are inconsistent (Qi et al., 2010; Xiang et al., 2012; Kim et al., 2012; Hu et al., 2013). Therefore, we conducted a hospital-based case-control study to investigate the role of miR-146aG $>C$ and miR-499A $>$ G polymorphisms on the risk of HCC in a Chinese population.

\section{MATERIAL AND METHODS}

\section{Study population}

A total of 184 subjects were enrolled in the study between January 2010 and February 2012 at Chengdu Military General Hospital. HCC was diagnosed by liver biopsy or the findings of at least 2 radiological tests for HCC, including abdominal ultrasound, spiral computed tomography, magnetic resonance imaging, and hepatic angiography. The control group consisted of 313 individuals randomly selected from the health examination center. A total of 184 age-matched control subjects were recruited from individuals who came to our hospital for a routine health check-up. None of the control subjects had a history of cancer, liver disease, or other digestive system disease.

The serum hepatitis B surface antigen and anti-hepatitis C virus antibody were evaluated using a microparticle enzyme immunoassay. Clinical and demographic characteristics of patients and control subjects were collected using a questionnaire designed for this study. This study was approved by the Ethnical Committee of Chengdu Military General Hospital, and a written informed consent form regarding the use of their blood samples for research studies was obtained from all participants.

\section{DNA extraction and genotyping}

All study participants were asked to provide $5 \mathrm{~mL}$ venous blood, and blood samples were stored at $-20^{\circ} \mathrm{C}$ until use. Genomic DNA was extracted using the TIANamp 
blood DNA kit (Tiangen Biotech, Beijing, China) according to manufacturer instructions. Duplex polymerase chain-reaction-restriction fragment length polymorphism with a confronting 2-pair primer was performed to determine the presence of the miR-146aG $>C$ and miR-499A $>$ G genotypes. The primers and products of miR-146aG $>C$ and miR-499A $>\mathrm{G}$ were designed using the Sequenom Assay Design 3.1 software (San Diego, CA, USA). The forward and reverse primers for miR-146aG $>$ C were 5'-CATGGGTTGTGTCAGTGTCAGAGCT-3' and 5'-TGCCTTCTGTCTCCAGTCTTCCAA-3', respectively. The forward and reverse primers for miR-499A $>$ G were 5'-CAAAGTCTTCACTTCCCTGCCA-3' and 5'-GATGTTTAAC TCCTCTCCACGTGATC-3', respectively. The polymerase chain reaction procedure was conducted with an initial melting step of $15 \mathrm{~min}$ at $95^{\circ} \mathrm{C}$, followed by 35 cycles at $94^{\circ} \mathrm{C}$ for $1 \mathrm{~min}, 55^{\circ} \mathrm{C}$ for $1 \mathrm{~min}$, and $72^{\circ} \mathrm{C}$ for $1 \mathrm{~min}$ for 49 cycles, and an elongation step for $10 \mathrm{~min}$ at $72^{\circ} \mathrm{C}$.

\section{Statistical analysis}

The analyses were performed using the computer software SPSS for Windows version 10.0 (SPSS, Inc., Chicago, IL, USA). Chi-square test ( $\chi^{2}$ test) was used to analyze categorical variables. $\chi^{2}$ test was used to assess Hardy-Weinberg equilibrium in controls for the genotypic frequencies of miR-146aG $>C$ and $\mathrm{miR}-499 \mathrm{~A}>\mathrm{G}$. The associations between the miR-146aG $>\mathrm{C}$ and $\mathrm{miR}-499 \mathrm{~A}>\mathrm{G}$ polymorphisms and risk of $\mathrm{HCC}$ were estimated using the odds ratios (OR) and their $95 \%$ confidence intervals $(95 \% \mathrm{CI})$ by conditional logistic regression analysis. The homozygous genotype was used as reference for to calculate ORs $(95 \% \mathrm{CI})$. A 2-sided P value $<0.05$ was considered to be statistically significant.

\section{RESULTS}

A total of 184 patients and control subjects were enrolled in our study; their general characteristics are summarized in Table 1. No significant difference was found between case

\begin{tabular}{|c|c|c|c|c|c|c|}
\hline \multirow[t]{2}{*}{ Variables } & Cases & $\%$ & Controls & $\%$ & \multirow[t]{2}{*}{$\chi^{2}$ or $t$} & \multirow[t]{2}{*}{$P$ value } \\
\hline & $\mathrm{N}=184$ & & $\mathrm{~N}=184$ & & & \\
\hline Age (year, mean $\pm \mathrm{SD})$ & $54.1 \pm 10.3$ & & $54.3 \pm 10.4$ & & 0.19 & 0.43 \\
\hline$<55$ & 98 & 53.26 & 99 & 53.80 & & \\
\hline$\geq 55$ & 86 & 46.74 & 85 & 46.20 & 0.01 & 0.92 \\
\hline \multicolumn{7}{|l|}{ Gender } \\
\hline Male & 126 & 68.48 & 126 & 68.48 & & \\
\hline Female & 58 & 31.52 & 58 & 31.52 & 0 & 1.00 \\
\hline \multicolumn{7}{|l|}{ Smoking } \\
\hline No & 117 & 63.59 & 128 & 69.57 & & \\
\hline Yes & 67 & 36.41 & 56 & 30.43 & 1.48 & 0.22 \\
\hline \multicolumn{7}{|l|}{ Drinking } \\
\hline No & 113 & 61.41 & 135 & 73.37 & & \\
\hline Yes & 71 & 38.59 & 49 & 26.63 & 5.98 & 0.01 \\
\hline \multicolumn{7}{|l|}{ Family history of cancer } \\
\hline No & 167 & 90.76 & 184 & 100.00 & & \\
\hline Yes & 17 & 9.24 & 0 & 0.00 & 17.82 & $<0.001$ \\
\hline \multicolumn{7}{|l|}{ Viral infection } \\
\hline No & 60 & 32.61 & 161 & 87.50 & & \\
\hline HBsAg-positive & 99 & 53.80 & 21 & 11.41 & & \\
\hline Anti-HCV Ab-positive & 21 & 11.41 & 3 & 1.63 & & \\
\hline Both positive & 4 & 2.17 & 0 & 0.00 & 114.36 & $<0.001$ \\
\hline
\end{tabular}


patients and control subjects with regard to age, gender, and smoking status. However, we found that patients were more likely to be drinkers, have family history of cancer, and have $\mathrm{HBV}$ and hepatitis $\mathrm{C}$ virus antibody infection (All $\mathrm{P}>0.05$ ).

The allele and genotype distributions of miR-146aG $>C$ and miR-499A $>$ G were in Hardy-Weinberg equilibrium in the control group, with $\mathrm{P}$ values of 0.21 and 0.78 , respectively (Table 2). There was no significant difference between genotypes, while the allele frequencies for miR-146aG $>C$ and miR-499A $>G$ were significantly different between cases and controls. Multivariate regression analyses showed that subjects carrying the miR-146a G allele and miR-499 G allele were associated with a non-significantly increased risk of HCC when compared with the homozygous allele, with an adjusted OR (95\%CI) of $1.38(0.97-1.84)$ and 1.40 (0.99-2.08), respectively.

Table 2. Genotype distributions of miR-146aG $>C$ and miR-499A $>\mathrm{G}$ between $\mathrm{HCC}$ patients and controls.

\begin{tabular}{|c|c|c|c|c|c|c|c|c|}
\hline \multirow[t]{2}{*}{ Genotype } & Controls & $\%$ & Cases & $\%$ & OR $(95 \% \mathrm{CI})$ & $P$ value & OR $(95 \% \mathrm{CI})^{1}$ & $\mathrm{P}$ value \\
\hline & $\mathrm{N}=184$ & & \multicolumn{6}{|l|}{$\mathrm{N}=184$} \\
\hline \multicolumn{9}{|c|}{$\mathrm{miR}-146 \mathrm{aG}>\mathrm{C}$} \\
\hline $\mathrm{CC}$ & 47 & 25.54 & 58 & 31.52 & 1.0 (Ref.) & - & 1.0 (Ref.) & - \\
\hline CG & 85 & 46.20 & 83 & 45.11 & $1.26(0.75-2.12)$ & 0.35 & $1.31(0.80-2.19)$ & 0.24 \\
\hline GG & 52 & 28.26 & 43 & 23.37 & $1.49(0.82-2.71)$ & 0.16 & $1.55(0.87-2.78)$ & 0.09 \\
\hline $\mathrm{C}$ allele & 178 & 48.64 & 199 & 54.08 & 1.0 (Ref.) & - & 1.0 (Ref.) & - \\
\hline $\mathrm{G}$ allele & 190 & 51.36 & 169 & 45.92 & $1.26(0.93-1.70)$ & 0.12 & $1.38(0.97-1.84)$ & 0.06 \\
\hline \multicolumn{9}{|c|}{$\operatorname{miR}-499 \mathrm{~A}>\mathrm{G}$} \\
\hline AA & 117 & 63.59 & 128 & 69.57 & 1.0 (Ref.) & - & 1.0 (Ref.) & - \\
\hline $\mathrm{AG}$ & 43 & 23.37 & 39 & 21.20 & $1.21(0.71-2.05)$ & 0.46 & $1.27(0.80-2.16)$ & 0.13 \\
\hline GG & 24 & 13.04 & 17 & 9.24 & $1.54(0.75-3.22)$ & 0.2 & $1.61(0.81-3.29)$ & 0.12 \\
\hline A allele & 277 & 75.27 & 296 & 80.16 & 1.0 (Ref.) & - & 1.0 (Ref.) & - \\
\hline $\mathrm{G}$ allele & 91 & 24.73 & 72 & 19.84 & $1.35(0.94-1.95)$ & 0.09 & $1.40(0.99-2.08)$ & 0.05 \\
\hline
\end{tabular}

${ }^{1}$ Adjusted for age, drinking, family history of cancer, and viral infection.

Further analysis was conducted to examine the interaction between $\mathrm{miR}-146 \mathrm{aG}>\mathrm{C}$ and miR-499A $>$ G and HBV infection (Table 3). Compared with the miR-499 A allele, subjects carrying the miR-499 A allele showed a greatly increased risk of HCC in subjects infected with HBV, with an adjusted OR $(95 \% \mathrm{CI})$ of 1.53 (1.34-2.41). However, we did not observe a significant association between $\mathrm{miR}-146 \mathrm{aG}>\mathrm{C}$ polymorphisms and $\mathrm{HBV}$ infection and $\mathrm{HCC}$ risk.

Table 3. miR-146aG $>C$ and miR-499A $>$ G polymorphisms and HCC risk stratified by HBV infection.

\begin{tabular}{|c|c|c|c|c|c|c|c|c|}
\hline Genotype & Controls & $\%$ & Not infected & $\%$ & OR $(95 \% \mathrm{CI})^{1}$ & HBV & $\%$ & OR $(95 \% \mathrm{CI})^{1}$ \\
\hline \multicolumn{9}{|c|}{$\overline{\mathrm{miR}-146 \mathrm{aG}>\mathrm{C}}$} \\
\hline $\mathrm{C}$ allele & 199 & 54.08 & 57 & 47.50 & 1.0 (Ref.) & 97 & 48.99 & 1.0 (Ref.) \\
\hline G allele & 169 & 45.92 & 63 & 52.50 & $1.37(0.91-2.06)$ & 101 & 51.01 & $1.37(0.97-2.03)$ \\
\hline \multicolumn{9}{|c|}{$\operatorname{miR}-499 \mathrm{~A}>\mathrm{G}$} \\
\hline A allele & 296 & 80.16 & 82 & 68.33 & 1.0 (Ref.) & 146 & 73.74 & 1.0 (Ref.) \\
\hline G allele & 72 & 19.84 & 38 & 31.67 & $1.95(1.13-3.04)$ & 52 & 26.26 & $1.53(1.34-2.41)$ \\
\hline
\end{tabular}

${ }^{1}$ Adjusted for age, drinking, and family history of cancer.

\section{DISCUSSION}

In China, HBV infection is highly endemic, and it is estimated that the prevalence of hepatitis B surface antigen in the population aged $1-59$ years is $9.8 \% ; 120$ million people are thought to carry the hepatitis B surface antigen (Xia et al., 1996; Dai and Qi, 1999). In this 
case-control study, we found that miR-146a G allele and miR-499 $\mathrm{G}$ allele were associated with a non-significantly increased risk of HCC, and that the miR-499 G allele showed an interaction with HBV infection.

Non-coding small RNAs can be used to reveal novel insights into the biological mechanism of HCC. Although the association between SNPs in protein-coding genes and cancer risk has been intensively examined, studies regarding the association between SNPs in miRNA genes and the risk of HCC have shown inconsistent results (Qi et al., 2010; Xiang et al., 2012; Kim et al., 2012; Hu et al., 2013). In this study, we did not find that the miR$146 \mathrm{aG}>\mathrm{C}$ and miR-499A $>\mathrm{G}$ polymorphisms significantly increased the risk of $\mathrm{HCC}$, but the miR-146a G allele and miR-499 G allele were slightly associated with an increased risk of $\mathrm{HCC}$. Previous studies indicated that the $\mathrm{miR}-146 \mathrm{aG}>\mathrm{C}$ polymorphisms were associated with the risk of various cancers, such as colorectal, breast, ovarian, and prostate cancer (Shen et al., 2008; Gao et al., 2011; Chae et al., 2013). Chae et al. (2013) reported that the miR-146a $\mathrm{CC}$ genotype was associated with an increased risk of colorectal cancer, while Xu et al. (2008; 2010) indicated that the miR-146a GG genotype was related to an increased risk of prostate cancer when compared with the CC genotype. Previously, 2 studies reported an association between miR-146aG $>$ C polymorphisms and HCC risk (Xu et al., 2008, 2010). However, our study only found a non-significant increased risk of HCC in individuals carrying the miR-146a $\mathrm{C}$ allele. The inconsistency of these studies can be explained by differences in the population background, source of control subjects, sample size, and by chance; therefore, these results require confirmation by additional studies.

miR-499 has been regarded as a predictive biomarker for carcinogenesis and plays a role in the development of cancer because it is involved in many biological processes, such as cellular senescence, apoptosis, inflammation, and immune response (Wang et al., 2011). Previous studies indicated that miR-499 may influence apoptosis and regulate p53 expression (Wang et al., 2011). A recent study showed that the level of miR-499 could be used as a predictor for the overall survival of non-small cell lung cancer patients (Hu et al., 2010). Another study indicated that high expression of miR-499 increased cell migration and invasion of colorectal cancer in vitro, as well as metastasis of lung and liver cancer in vivo (Akkiz et al., 2011). Previous studies showed that the miR-499A $>$ G polymorphism plays a role in the risk of HCC (Akkiz et al., 2011; Zhou et al., 2012). In our study, we found a non-significant association between the miR-499A $>$ G polymorphism and risk of $\mathrm{HCC}$. The negative results may have resulted from the small sample size, and thus further large-scale studies are necessary.

Moreover, we found that the miR-499A $>$ G polymorphism interacts with HBV infection. A previous study indicated that the miR-499A $>\mathrm{G}$ polymorphism is strongly affected by HBV mutations (Han et al., 2013), indicating that HBV mutation has a synergistic effect with miR-499A $>\mathrm{G}$ polymorphism on the risk of $\mathrm{HCC}$.

In conclusion, we found that the miR-146a G allele and miR-499 $\mathrm{G}$ allele were associated with a non-significant increased risk of HCC, and subjects carrying the miR-499 A allele genotype and HBV showed a greatly increased risk of HCC. Therefore, the miR-146aG $>C$ and miR-499A $>$ G polymorphisms are not related to the genetic susceptibility to HCC. Further independent studies are necessary to validate our findings in a larger sample size.

\section{REFERENCES}

Akkiz H, Bayram S, Bekar A, Akgöllü E, et al. (2011). Genetic variation in the microRNA-499 gene and hepatocellular 
carcinoma risk in a Turkish population: lack of any association in a case-control study. 12: 3107-3112.

Bartel DP (2004). MicroRNAs: genomics, biogenesis, mechanism, and function. Cell 116: 281-297.

Chae YS, Kim JG, Lee SJ, Kang BW, et al (2013). A miR-146a polymorphism (rs2910164) predicts risk of and survival from colorectal cancer. Anticancer Res. 33: 3233-3239.

Dai ZC and Qi GM (1999). Viral hepatitis in China: seroepidemiological survey in Chinese population, 1992-1995 (part one). Beijing: Scientific and Technical Documents: 39-59.

Davila JA, Morgan RO, Shaib Y, McGlynn KA, et al. (2004). Hepatitis C infection and the increasing incidence of hepatocellular carcinoma: a population-based study. Gastroenterology 127: 1372-1380.

Farazi PA and DePinho RA (2006). Hepatocellular carcinoma pathogenesis: from genes to environment. Nat. Rev. Cancer 6: 674-687.

Gao LB, Bai P, Pan XM, Jia J, et al. (2011). The association between two polymorphisms in pre-miRNAs and breast cancer risk: a meta-analysis. Breast Cancer Res. Treat. 125: 571-574.

Han Y, Pu R, Han X, Zhao J, et al. (2013). Associations of pri-miR-34b/c and pre-miR-196a2 polymorphisms and their multiplicative interactions with hepatitis B virus mutations with hepatocellular carcinoma risk. PLoS One 8: e58564.

He L and Hannon GJ (2004). MicroRNAs: small RNAs with a big role in gene regulation. Nat. Rev. Genet. 5: 522-531.

He B, Pan Y, Cho WC, Xu Y, et al. (2012). The association between four genetic variants in microRNAs (rs 11614913, rs 2910164, rs 3746444, rs 2292832) and cancer risk: evidence from published studies. PLoS One 7: e49032.

Hu Z, Liang J, Wang Z, Tian T, et al. (2009). Common genetic variants in pre-microRNAs were associated with increased risk of breast cancer in Chinese women. Hum. Mutat. 30: 79-84.

Hu Z, Chen X, Zhao Y, Tian T, et al. (2010). Serum microRNA signatures identified in a genome-wide serum microRNA expression profiling predict survival of non-small-cell lung cancer. J. Clin. Oncol. 28: 1721-1726.

$\mathrm{Hu}$ M, Zhao L, Hu S and Yang J (2013). The association between two common polymorphisms in microRNAs and hepatocellular carcinoma risk in Asian population. PLoS One 8: e57012.

Kao JH and Chen DS (2002). Global control of hepatitis B virus infection. Lancet Infect. Dis. 2: 395-403.

Kim WH, Min KT, Jeon YJ, Kwon CI, et al. (2012). Association study of microRNA polymorphisms with hepatocellular carcinoma in Korean population. Gene 504: 92-97.

Lim LP, Lau NC, Garrett-Engele P, Grimson A, et al. (2005). Microarray analysis shows that some microRNAs downregulate large numbers of target mRNAs. Nature 433: 769-773.

Loktionov A (2004). Common gene polymorphisms, cancer progression and prognosis. Cancer Lett. 208: 1-33

Qi P, Dou TH, Geng L, Zhou FG, et al. (2010). Association of a variant in MIR 196A2 with susceptibility to hepatocellular carcinoma in male Chinese patients with chronic hepatitis B virus infection. Hum. Immunol. 71: 621-626.

Shen J, Ambrosone CB, DiCioccio RA, Odunsi K, et al. (2008). A functional polymorphism in the miR-146a gene and age of familial breast/ovarian cancer diagnosis. Carcinogenesis 29: 1963-1966.

Wilfred BR, Wang WX and Nelson PT (2007). Energizing miRNA research: a review of the role of miRNAs in lipid metabolism, with a prediction that miR-103/107 regulates human metabolic pathways. Mol. Genet. Metab. 91: 209217.

Wang JX, Jiao JQ, Li Q, Long B, et al. (2011). miR-499 regulates mitochondrial dynamics by targeting calcineurin and dynamin-related protein-1. Nat. Med. 17: 71-78.

Xiang Y, Fan S, Cao J, Huang S, et al. (2012). Association of the microRNA-499 variants with susceptibility to hepatocellular carcinoma in a Chinese population. Mol. Biol. Rep. 39: 7019-7023.

Xia GL, Liu CB, Cao HL, Bi SL, et al. (1996). Prevalence of hepatitis B and C virus infections in general Chinese population. Results from a nationwide cross-sectional seroepidemiologic study of hepatitis A, B, C, D, and E virus infections in China, 1992. Int. Hepatol. Commun. 5: 62-73.

Xu B, Feng NH, Li PC, Tao J, et al. (2010). A functional polymorphism in Pre-miR-146a gene is associated with prostate cancer risk and mature miR-146a expression in vivo. Prostate 70: 467-472.

Xu T, Zhu Y, Wei QK, Yuan Y, et al. (2008). A functional polymorphism in the miR-146a gene is associated with the risk for hepatocellular carcinoma. Carcinogenesis 29: 2126-2131.

Yu MC and Yuan JM (2004). Environmental factors and risk for hepatocellular carcinoma. Gastroenterology 127: S72-S78.

Zhou J, Lv R, Song X, Li D, et al. (2012). Association between two genetic variants in miRNA and primary liver cancer risk in the Chinese population. DNA Cell. Biol. 31: 524-530. 